\title{
Determining the Impacts of Educational Intervention based on PLST Extended Care on Caregiving Methods and Improved Exposure to Challenging Behaviors of People with Dementia (PWD): A mixed- methods study
}

Fereshteh Zamani-Alavijeh

Isfahan University of Medical Sciences

Shakiba Zahed ( $\nabla$ shakiba.zahed64@gmail.com )

Isfahan University of Medical Sciences

Maryam Emami

Isfahan University of Medical Sciences

Shahrzad Bazargan-Hejazi

Charles Drew University of Medicine and Science, the University of California at Los Angeles (UCLA)

Majid Barekatain

Isfahan University of Medical Sciences

Akbar Hassanzadeh

Isfahan University of Medical Sciences

AhmadAli Eslami

Isfahan University of Medical Sciences

\section{Research Article}

Keywords: Educational intervention, PLST care model, Challenging behaviors, People with dementia (PWD)

Posted Date: December 15th, 2021

DOI: https://doi.org/10.21203/rs.3.rs-969789/v2

License: (c) (1) This work is licensed under a Creative Commons Attribution 4.0 International License.

Read Full License 


\section{Abstract}

\section{Background}

Psychological events in people with dementia (PWD) lead to behavioral disorders that require targeted planning for caregivers on how to adapt to these behaviors. A progressively lowered stress threshold (PLST) model provides effective interventions for caregivers to adapt to the behaviors of people with dementia (PWD). Therefore, this study aims to determine the impacts of educational intervention based on the progressively lowered stress threshold extended (PLSTE) model on the caregiving of people with dementia (PWD) in Isfahan, Iran.

Methods

This exploratory mixed methods study was initially conducted with a qualitative approach to content analysis type from May 2016 to June 2018. Data were collected in a qualitative stage through in-depth nonstructured interviews with 29 People with Dementia (PWD)'s caregivers using the "new comment" command and then analyzed. The researcher designed a multisectional questionnaire, including demographic characteristics, knowledge measurement, and monitoring the practice of caregivers. The validity of the questionnaire was verified by a panel of experts, and its reliability was confirmed using the Cronbach alpha coefficient (knowledge section 0.838 and practice section 0.802). To adjust the intervention program, the educational content based on the PLSTE model was used for 38 caregivers available at two elderly nursing centers in Isfahan. This educational intervention was designed and managed for the first time in our community. None of the caregivers agreed to refuse to receive the educational content, So the evaluation of the program lacks a randomized controlled group. The data were collected immediately and one month after the educational intervention using a questionnaire.

Results

According to the results of the qualitative section of this study, the researcher was able to add a cultural and belief class and then the related intervention method to the PLST model. In the quantitative part, paired t-test indicated that the mean scores of knowledge, caregiving practice, and exposure to Challenging Behaviors (CB) in all dimensions of practice immediately and one a month after intervention were significantly higher than the mean scores before intervention $(P<0.05)$.

\section{Conclusion}

Considering the impacts of this intervention, educating caregivers with PLST extended the care model is recommended, with a specific focus on cultural and traditional issues of society, to improve the knowledge and practice of caregivers in caregiving skills and appropriate exposure to challenging behaviors people with dementia (CBPWD).

Trial registration No. IRCT20180421039370N1 -2019-01-11-http://www.irct.ir 


\section{Background}

Dementia is a progressive cerebrovascular disease that places a huge burden on patients, caregivers, families, and health systems. As many as 44 million people in the world suffer from this disease, and it will reach 65 million in 2030(1). The most recent descriptive epidemiological research into dementia is enabling investigation into how the prevalence and incidence are changing over time (2). The prevalence of this disease in Iran is higher than in many other countries, but its level of detection is lower. In 2011, the prevalence of people with dementia (PWD) in Iran was estimated to be 300,000 , which doubles in number every 5 years. Therefore, the number of people with dementia (PWD) in Iran currently appears to be approximately 700,000 (3). Symptoms include memory problems, disruptions in daily activities, and increased dependence on caregivers (4-6). Psychological events, such as delusions, illusions, and distressed states, are also considered major stressors for both the patient and caregivers, with at least half of people with dementia (PWD) experiencing these psychological events and increasing with the progression of the disease (7). Patients' psychological behaviors are hardly understandable and controllable, and their sharp edges tend to be more toward caregivers (8). A large percentage of the experiences of psychological events in patients lead to behavioral disorders and increased stress in the caregiving process (8), so many caregivers reported severe behavioral abnormalities associated with specific psychological events during their caregiving experience (7). Some studies have specified the reasons for CBPWD to be neglected needs of patients, communication problems between the patient and the caregiver, lack of knowledge of caregivers and surrounding people, misallocation of resources by caregivers, and professionals and policymakers concerning the needs of People with Dementia (PWD) (9).

$\mathrm{CB}$ in patients is the most important reason for keeping some of them in elderly nursery homes. These kinds of behaviors, especially agitation and aggression, lead to loss of quality of life, stress, and burden on caregivers (formal and informal). Therefore, management of the CB of patients living in elderly nursery homes is one of the most basic approaches (10). Some family caregivers also design and implement strategies to reduce stress and resolve the needs of both parties to control the symptoms of dementia and behavioral symptoms (11). In this regard, the PLST model was initially set up to organize observations to help caregivers and caregiving decisions (12). This model is derived from psychological theories, including stress, adaptability, copying, matching, and behavioral and psychological research. PLST is a model for better understanding and management of patients' behaviors by family caregivers and health care professionals, which trains effective interventions for caregiver compliance with the $\mathrm{CB}$ of patients $(8,13)(12)$. This model has a significant impact on increased knowledge about the $C B$ of patients and the caregivers' practice and reduces the negative aspects of the caregiving process (13). Despite wide explanation and demonstration of the effectiveness of short-term educational interventions in the world, there has been very little research on the quality of life of people with dementia (PWD), their families, and their caregivers in the process of caregiving and providence of services in Iran. Therefore, due to the important role of family and official caregivers in supporting and providing caregiving services to patients with physical and mental disorders in Iranian culture and the lack of an appropriate supportive and educational system for caregivers of people with dementia (PWD) in the health system of the 
country, this study aims to determine the impacts of educational interventions based on the PLSTE model on caregiving methods and improved exposure to CBPWD in Isfahan - Iran - for the first time.

\section{Methods}

\section{Study Design}

This exploratory mixed methods study was initially conducted from May 2016 to June 2018 in three stages. The first phase of the study was conducted using a qualitative approach to the content analysis methodology to expand and complete the PLST model. Then, in the second stage, the researcher made a multisectional questionnaire using a standard questionnaire and the results of a qualitative study. Finally, the educational intervention was carried out using a pretest-posttest group based on the educational needs of caregivers resulting from qualitative study and within the framework of the PLSTE model with the aim of improving caregivers' practice, caregiving skills, and dealing with CBPWD.

\section{Informants}

Key informants (14) in the qualitative phase of the study were caregivers of People with Dementia (PWD). Caregivers were people whose patients had a case with a psychiatrist or in an educational hospital. It should be noted that some caregivers were serving at home and some in the elderly nursery homes (primary caregiving). Other informants (14) were those who had somehow entered the course of the disease, including the family of patients. An in-depth unstructured interview was conducted with 29 caregivers as a sample to reach data saturation.

The inclusion criteria of the study were all caregivers who had at least 6 months of experience taking care of people with dementia (PWD). We were interested in participating in the study. We were willing to express their experiences and completed and signed the written consent form. Refusing to collaborate with the researcher and interviewing were exclusion criteria. A total of 33 informants were enrolled in the study, of which four were excluded from the study due to lack of inclusion criteria and non-participation. To select the informants, the scholar referred to accessible and qualified caregivers personally and invited them to participate in the study.

\section{How to Conduct Interviews and Collect Data in the Qualitative Phase}

In this study, the corresponding author (SZ) was responsible for conducting the interview. Interviews with participants were done by phone or face to face. Before the interview, caregivers were asked to express their basic demographic information, including age, sex, marital status, level of education, length and hours of caregiving, and previous caregiving experience, as outlined in Table 1. Interviews were conducted only in the presence of the researcher without the presence of others. At the beginning of each interview, the research objectives were explained to the participants, and for the interviews to be recorded, verbal consent was obtained. At the end of each interview, the consent of the participants was recalled according to the issues mentioned in the interview. The interviews started with some questions for more 
familiarity and a more intimate climate and then continued with asking about the caregiving experience of the informants about taking care of people with dementia (PWD). According to the informants' experiences, the next questions were not predicted, and the patient was asked according to the previous conversation. The interviews were recorded by the recorder and immediately transcribed in Microsoft Word. After transcribing the interviews and reviewing them by the authors, 4 interviews were repeated due to the need to obtain more information from the caregivers.

\section{Sampling Procedure and Sample Size in Quantitative Phase}

With the aim of conducting the intervention and determining the sample size in this phase, two groups of family and official caregivers were selected due to limited access to caregivers. The sample size was estimated to be 32 informants by $\quad n=(z a / 2+z \beta){ }^{2} S^{2} / d^{2}$ formula (factor of safety $95 \%$ and test

coefficient $80 \%$ ). This number was increased to 38 informants due to reduction during the intervention and in the follow-up phase. The inclusion and exclusion criteria were the same as those in the qualitative phase. To select the samples, the available files of People with Dementia (PWD) in educational hospitals affiliated with Isfahan University of Medical Sciences and psychiatrists' offices were reviewed. Six family caregivers and 32 caregivers working in elderly nursery centers were willing to participate in the study. This educational intervention was designed and managed for the first time in our community. None of the caregivers agreed to refuse to receive the educational content, So the evaluation of the program lacks a randomized controlled group

\section{Data Analysis}

According to the first (FZ) and second (SZ) authors' experiences in conducting qualitative research, they were more involved in data analysis. Interviews were transcribed for analysis using the "new comment" command and Microsoft Word. The text of each interview was carefully studied, and after breaking the text, first-level codes were extracted. Primary codes were categorized based on similarities and differences, and by titling each class and repeating the classification and merging of similar codes, and adding newly generated codes, second-level codes were extracted. Finally, the main themes were produced and classified. When all the data were coded and agreed upon for the classes, each class was also examined for saturation.

\section{Scientific Trustworthiness of the Results}

Regarding trustworthiness $(14,15,16)$, credibility, dependability, conformability, transferability, and authenticity were applied. To apply trustworthiness in the whole study, the researcher attempted to collect and analyze appropriate data with the maximum variety (official and family caregivers) according to Lincoln and Guba criteria to reach saturation. The process of data analysis was a reciprocal continuous rotational comparison, and to control any ambiguity, the data were controlled by the members themselves (Member Check). The codes obtained from the Peer Check and External Check methods by the authors' 
team were revised and modified in the presence of five experienced professors in the field of qualitative studies and psychiatric professors (14) (17).

\section{Expansion of the PLST Model}

By analyzing qualitative data, the researchers eventually created a new class and intervention for the PLST model by using one of the generated classes.

\section{Educational Intervention based on PLST Extended Model}

The educational sessions were held in the halls of the two elderly nursery centers of Sadeghieh and Rangin Kaman-sefid in Isfahan. The educational intervention was designed and carried out based on the educational needs of caregivers at all stages of taking care of people with dementia (PWD). In the initial and qualitative phases of this study, these factors were identified as the main needs of caregivers. Therefore, by analyzing qualitative data, the researchers extracted the educational needs of both knowledge and practice skills, adapted the educational content to the extended PLST model, and then used them during the intervention.

The intervention was provided by a team of psychiatrists, health education and health promotion experts, an elderly health research line, and a psychologist. The intervention group received the required education in 8 sessions of 2 hours and in groups of 13 and 12 persons. Educational sessions provided correct information to caregivers, focusing on knowledge from the nature and course of People with Dementia (PWD), the impact of the disease on the patient's religious and cultural capabilities, caregiving education according to the needs and daily activities of the patient, caregiving in connection with practice and psychological disorders of the patients, and caregiving according to high-risk and unsafe behaviors of the patients. In fact, with this intervention, caregivers obtain extensive education in the fields of caregiving management and planning, people with dementia (PWD), possible preventions, processes and courses of the disease, methods of increasing self-efficacy, and many other skills in the extended and systematic framework of PLST (Table 5).

To increase the knowledge of caregivers, the strategy of expressing successful and unsuccessful experiences of the caregivers (successive experiences) and mentioning different examples of different behaviors of patients and strategies used by caregivers to expose the CB of patients were useful. Since stigma or shame of occurrence of some unusual behaviors of patients is considered the most important barrier to caregiving, educating caregivers to improve communication skills, reduce negative emotions, correct mental errors, and replace positive thoughts were used to improve and upgrade the caregiving process. These sessions were conducted in the form of speeches, questions and answers, role plays, educational video clips, persuasions, and verbal encouragements. After the intervention, the caregivers received follow-up and telephone counseling for 1 month.

\section{Data Collection Method in the Quantitative Phase}


Data were collected using a questionnaire made by the researcher. This questionnaire was designed with the help of data from a qualitative study, some of the questions of the standard questionnaire (18), and another similar study (19).

The first part of the questionnaire included 12 questions about demographic characteristics. The second part of the tool was a questionnaire made by the researcher (containing 30 questions) to assess the caregivers' knowledge about the nature and course of the disease and how to take care of people with dementia (PWD), which was designed based on the qualitative study phase. The third part was concerned about measuring behavioral skills with the Likert method (never, seldom, sometimes, often, always from 4 to zero) in three caregiving fields of daily and physical needs of the patients, needsbased on practice and mental disorders, and caregiving for risky and safety behaviors of the patient.

Determining the qualitative formal and qualitative validity of the questionnaire was done by a panel of 14 experts in health education, promotion of health, and psychiatry. The CVI and CVR of the questionnaire were 0.99 and 0.88 , respectively. Additionally, for the reliability of instruments, a test-retest method with a time interval of 3 weeks was used with 29 caregivers. The reliability coefficients of the knowledge and behavior questions were 0.843 and 0.819 , respectively. The reliability coefficient of behavior questions was separately evaluated in three different fields of caregiving: caregiving based on physical and daily needs of the patient (0.776), caregiving based on practice and psychological disorders of the patient (0.728), and caregiving based on risky and unsafe behaviors of the patient (0.759).

Data Analysis Method for Quantitative Phase

The collected data were coded into a computer and analyzed by SPSS statistical software version 18 . In this regard, Pearson and Spearman correlation coefficients, independent t-tests, paired t-tests, and multiple regression models were used to determine the type and severity of the relationship between dependent variables and independent variables.

\section{Results}

\section{Results of the Quantitative Phase}

The study population included 29 caregivers of People with Dementia (PWD) (including 4 males and 25 females) whose demographic characteristics are presented in Table 1. The researcher obtained 6 categories by analyzing the interviews ( 1454 codes). One of them was religious and cultural education leading to the formation of a class and intervention in the PLST model (Table 5).

This new class is based on qualitative data titled "respect for the belief and religious attitudes remaining in the patient's mind". Therefore, the caregiver must avoid debates such as the time and place of religious practices (such as reading prayers, fasting, etc.) according to the patient's circumstances. However, some patients are interested in saying their prayers, reading the Qur'an, etc. However, because of memory and speech impairment, they are not able to perform it correctly and on time. In this case, to commemorate 
ablution, prayer, and daily worships, caregivers or patient families should slowly perform them in the presence of the patient or should prepare some conditions for reading verses of Quran or Adan aloud at certain times in the patient's place of residence. To create the proper conditions for cleansing according to the patient's mental restraints, principles of cleanliness of clothes, living place, and activities of the patient should be carefully monitored. They should provide conditions to carry out traditional cultural and religious symbolic activities, which are the survivors of the old memories for the patient, such as putting henna on the hands of female patients, participating Attend poetry nights especially for male patients (Reciting Shahnameh and Hafez), schedule outings and short excursions with the caregivers in pleasant and historical locations with extensive care and limited time.

\section{Results of the Quantitative Phase}

The age range of caregivers was 23 to 56 years old with a mean of $40.9 \pm 9.1$ years. The mean caregiving duration was $4.5 \pm 3.3$ years, the mean daily caregiving duration was $8.5 \pm 2.2$ hours, and the average duration of caregiving for the current patient was $5.1 \pm 3.8$ years. Other demographic characteristics of the patients are presented in Table 2. A paired t-test indicated that the mean scores of knowledge and practice along with its dimensions were significantly increased after the intervention in comparison with the scores before the intervention $(P<0.05)$ (Table 3$)$. The Pearson correlation coefficient indicated that the caregiver's knowledge score was not significantly correlated with age, years of caregiving, or daily caregiving hours. The total score of caregiver practice had a direct relationship with daily hours of caregiving from people with dementia (PWD) $(P<0.05)$; however, it had no significant relationship with age, years of caregiving, or duration of caregiving (Table 4). Independent t-tests indicated that the mean scores of knowledge (48.3 and 54.4 in males and females, respectively) and the mean score of practice (67.8 and 64.2 in males and females, respectively) were not significantly different between males and female caregivers.

\section{Discussion}

CBPWD may have adverse consequences such as stress, weakness of spirituality, job dissatisfaction, and sequential absences of nurses working in health care centers taking care of patients with dementia. Educational programs for nursing staff who take care of these patients for a long time may reduce these effects and help caregivers manage the $\mathrm{CB}(20,21)$. The common behavioral and psychological symptoms of dementia are very stressful and challenging for family caregivers. However, the specific strategies that caregivers use to manage these psychological and behavioral symptoms are relatively unknown (11). Knowledge of stressful factors can help elderly nursery caregivers manage their caregiving process. This leads to a quick assessment after a mental illness or during a patient's practice impairment (8). Therefore, since educational interventions based on the PLST care model for elderly individuals with dementia are a research gap in Iran due to cultural and ethical conditions, patients' cultural and religious beliefs are added to the PLST model (Table 5). Respect for the belief and religious attitudes remaining in the patient's mind and providence of conditions to carry out traditional cultural and religious symbolic activities, etc., which are survivors of old memories in the patient's mind, and 
observance of strategies for adapting caregivers with $\mathrm{CB}$ of the patients are among the innovations of this study added to the model along with some other classes and interventions. This model teaches effective interventions for caregivers to adapt to the behaviors of people with dementia (PWD). This conceptual model is used for community-based studies of family caregivers People with Dementia (PWD) contributing to family and organizational caregiving. Elderly nurses educate caregivers of people with dementia (PWD) about the symptoms and behavioral challenges of patients and coping methods so that they can have an idea of a long-term and targeted caregiving process $(8,13)$. Therefore, over time and with the advancement of the disease, some patients experience problems understanding customary issues, especially religious issues and due to widespread customary and cultural issues in Iranian society, caregivers should have good knowledge and attitudes (22). In this field to be able to deal with them. The PLST extended care model can help caregivers improve their caregiving provisions.

According to the results of this study, most caregivers were women in both studies. In many domestic and international studies, it has also been pointed out that women make up the largest share of professional careers in the field of dementia caregiving (23-25). Consistent with this study, some other studies indicated that women who take care of their husbands endure more pressure and are highly vulnerable to emotional problems (23). Women who take care of their husbands with dementia rarely identify themselves as caregivers; caregiving is a label used for services. The caregiving role is considered an extension of a lifelong commitment to family care. The transition to a caregiver role can be difficult and confusing, requiring a reassessment of relationships and understanding of behavioral change (23).

This is the first time that this care model is used to educate caregivers of people with dementia (PWD) in Iran. The model also has cultural and belief classes. Therefore, its interventions can be considered (strength points) of study and are of interest to female caregivers as well as to most societies with similar religious and cultural conditions. The results of the educational intervention based on the extended model indicated that the mean scores of knowledge and practice along with its dimensions were significantly increased after the intervention in comparison with the scores before the intervention. There were also some other studies with similar results and the number of people in the PLST model of the present study $(8,26)$. The results of the study showed that the total caregiver practice score was directly related to daily caregiving for people with dementia (PWD). It seems that spending more time taking care of people with dementia (PWD) will enhance coping skills and caregivers' compliance strategies with CB. Some of the studies confirm our results $(8)(27,28)$. The Spearman correlation coefficient indicated that the level of education of caregivers had a direct correlation with the total practice score. According to the results of the present study, it seems that a higher level of education and caregivers' knowledge promote the ability to acquire caregiving and self-efficacy skills in dealing with the patient's challenging behavior in the fields of psychological, high risk, and unsafe behaviors. In line with our results, some other studies emphasized the role of education in building communication skills. In fact, according to the findings of the present study, caregivers with higher education levels can provide better care.

The results of this study indicated that there was no significant difference between mean scores of knowledge and practice in male and female caregivers; however, in some other studies, it has been 
pointed out that women's knowledge background from dementia is less than that of men (29). Therefore, studies show that interventional programs are necessary and cost-effective for improving the caregiving process $(29,30)$. Therefore, it is recommended to differentiate between the type, method, and content of educational programs for male and female caregivers. Health education programs will need to be targeted differently towards male and female health behaviors (23).

Development of the PLST model and its localization following the cultural and belief conditions of Iran and other cultures with similar beliefs. One of the strengths of this study is to diminish stigma and prejudice due to the unusual behaviors and speech of the People with Dementia (PWD) that were explained to caregivers by the educator, and they became completely aware of it. This is the first time that the PLST educational model has been used in caregiving interventions in Iranian society. Due to the lack of cooperation of authorities of elderly nursery centers, which take care of people with dementia (PWD), and the lack of a specific organ or organization for accessing caregivers of people with dementia (PWD), the researcher encountered some limitations.

\section{Conclusion}

The results of this study indicate the positive impacts of educational interventions, including the caregiving table of the PLST extended care model, on improving the knowledge and practice of official and family caregivers of people with dementia (PWD). It seems that these interventions improve the knowledge and evaluation of caregivers by increasing the problems of patients and therefore have led to improved, accurate, and appropriate practice skills of caregivers toward service recipients, resulting in potential improvement of quality of life for both patients and their caregivers. Therefore, it is recommended that community-based educational programs, elderly nursery centers for people with dementia (PWD) welfare centers, and other related institutions for caregivers be designed and implemented according to the age, gender, education level, and other demographic characteristics of caregivers. Since the present study takes belief and cultural structures into consideration, the researcher believes that educational intervention based on the PLST extended model can be used in societies with similar cultures.

\section{Abbreviations}

PLST Model: Progressively Lowered Stress Threshold Model

PLSTE: Progressively Lowered Stress Threshold Extended model

PWD: People with Dementia (PWD)

CB: Challenging Behaviors

CBPWD: Challenging Behaviors of People with Dementia 


\section{Declarations}

\section{Ethics approval and consent to participate}

This study received the ethics committee of the Isfahan University of Medical Sciences approval. The Code of Ethics is IR.MUI.REC.1395.3.204, and the project number is 395204.

'Informed consent' was obtained from all participants prior to conducting the educational intervention and qualitative interviews.

My submission was performed in accordance with the relevant guidelines and regulations (Declaration of Helsinki).

All methods were carried out in accordance with [relevant guidelines and regulations]."

\section{Consent for publication}

They were ensured of the confidentiality of data, their right to withdraw from the study at any stage, and the researchers' respect for privacy in analyzing and managing their data.

It is not any applications for this study. Not applicable

\section{Availability of data and material}

The interviews are not publicly available due to the protection of participant confidentiality. However, quantitative data are available in the form of an SPSS file. If someone wants to request the data from this study, by sending an email to the corresponding author should be contacted.

\section{Competing interests}

The authors declare that they have no competing interests.

\section{Funding}

This study was funded by the Student Research Center, School of Health, Isfahan University of Medical Sciences, Isfahan, Iran.

\section{Authors' contributions}

1. (F. Z-A), Contributed to the collection of data, the concept of the paper, the review of the literature, discussion of the results, and writing the article.

2. (Sh. Z) **, Ph.D., Contributed to the supervision of the collection of data, the concept and development of the paper, the discussion of the results, and writing the article. 
3. (ME \& Sh H-B), Contributed to the critical review of the manuscript, the discussion of the results, and the concept of the paper.

4. (M. B), Contributed to the critical review of the manuscript, the discussion of the results, the concept of the paper, and the critical review of the manuscript

5. (A. H), Contributed to Data analysis \& Statistical analysis

6. (AA. E), Contributed to the supervision of the collection of data, the critical review of the manuscript, and the discussion of the results.

All the authors have read and approved the final manuscript.

\section{Acknowledgments}

The authors wish to express their gratitude to the patients, their families and caregivers, and the staff at the selected retirement homes (Sadeghieh, Milad Noor, and Rangin Kaman sefid -Isfahan) for their cooperation and help in conducting this study. and to Dr. Geri Richards Hall Clinical Nurse Specialist for developing the "Progressively Lowered Stress Threshold Model (PLST).

\section{References}

1. Qiu C, Fratiglioni L. Epidemiology of Alzheimer's. Alzheimer's Disease. 2017.

2. Wu Y-T, Beiser AS, Breteler MM, Fratiglioni L, Helmer $\mathrm{C}$, Hendrie HC, et al. The changing prevalence and incidence of dementia over time-current evidence. Nature Reviews Neurology. 2017;13(6):327.

3. Sharifi F, Fakhrzadeh H, Vannaghani M, Arzaghi SM, Khoei MA, Farzadfar F, et al. Prevalence of Dementia and Associated Factors among Older Adults in Iran: National Elderly Health Survey (NEHS). Archives of Iranian Medicine (AIM). 2016;19(12).

4. Association As. 2018 Alzheimer's disease facts and figures. Alzheimer's \& Dementia. 2018;14(3):367429.

5. Langa KM. Is the risk of Alzheimer's disease and dementia declining? Alzheimer's research \& therapy. 2015;7(1):34.

6. Brookmeyer R, Johnson E, Ziegler-Graham K, Arrighi HM. Forecasting the global burden of Alzheimer's disease. Alzheimer's \& dementia. 2007;3(3):186-91.

7. Buckwalter KC, Gerdner L, Kohout F, Hall GR, Kelly A, Richards B, et al. A nursing intervention to decrease depression in family caregivers of persons with dementia. Archives of Psychiatric Nursing. 1999;13(2):80-8. 
8. Lindsey PL, Buckwalter KC. Psychotic events in Alzheimer's disease: application of the PLST model. Journal of gerontological nursing. 2009;35(8):20-7.

9. Cohen-Mansfield J, Mintzer JE. Time for change: the role of nonpharmacological interventions in treating behavior problems in nursing home residents with dementia. Alzheimer Disease \& Associated Disorders. 2005;19(1):37-40.

10. Smalbrugge M, Zwijsen SA, Koopmans RC, Gerritsen DL. Challenging Behavior in Nursing Home Residents with Dementia. Dementia in Nursing Homes: Springer; 2017. p. 55-66.

11. Polenick CA, Struble LM, Stanislawski B, Turnwald M, Broderick B, Gitlin LN, et al. "I've learned to just go with the flow": Family caregivers' strategies for managing behavioral and psychological symptoms of dementia. Dementia. 2018:1471301218780768.

12. Hall GR, Gerdner L, Zwygart-Stauffacher M, Buckwalter KC. Principles of nonpharmacological management: Caring for people with Alzheimer's disease using a conceptual model. Psychiatric Annals. 1995;25(7):432-40.

13. Söylemez BA, Küçükgüçlü Ö, Buckwalter KC. Application of the Progressively Lowered Stress Threshold Model with Community-Based Caregivers: A Randomized Controlled Trial. Journal of gerontological nursing. 2016.

14. Polit D, Hungler B. Essentials of nursing research: Methods, appraisal, asid utilization. 1994.

15. Elo S, Kääriäinen M, Kanste O, Pölkki T, Utriainen K, Kyngäs H. Qualitative content analysis: A focus on trustworthiness. SAGE open. 2014;4(1):2158244014522633.

16. Elo $\mathrm{S}$, Kyngäs $\mathrm{H}$. The qualitative content analysis process. Journal of advanced nursing. 2008;62(1):107-15.

17. Guba E, Lincoln Y. Criteria for assessing the trustworthiness of naturalistic inquiries. ECTJ. 1981; 29: 75e91. 2015.

18. KERTESZ A, NADKARNI N, DAVIDSON W, THOMAS AW. The Frontal Behavioral Inventory in the differential diagnosis of frontotemporal dementia. Journal of the International Neuropsychological Society. 2000;6(4):460-8.

19. Chrabaszcz M. Preventing Dysfunctional Behaviors of Those with Dementia Based on the Progressively Lowered Stress Threshold Model. 2014.

20. Hazelhof TJ, Gerritsen DL, Schoonhoven L, Koopmans RT. "The educating nursing staff effectively (TENSE) study”: design of a cluster randomized controlled trial. BMC nursing. 2014;13(1):46.

21. Aguilar A. DEMENTIA CARE OF INPATIENT UNITS. 2016. 
22. Stolley JM, Buckwalter KC, Koenig HG. Prayer and religious coping for caregivers of persons with Alzheimer's disease and related disorders. American Journal of Alzheimer's Disease. 1999;14(3):181-91.

23. Erol R, Brooker D, Peel E. Women and dementia: A global research review. 2015.

24. Erol R, Brooker D, Peel E. The impact of dementia on women internationally: An integrative review. Health care for women international. 2016;37(12):1320-41.

25. Mazloomi-Mahmoodabad S, Zahed S, Emami M, Barekatain M, Shahnazi H, Mahaki B. A study on the evaluation of relationship between the predisposing factors and practice and demographic variables in caregivers of patients with Alzheimer's diseases. Journal of Isfahan Medical School. 2015;33(329).

26. Aguilar A. Coping with Behavioral Symptoms of Dementia: Educating Caregivers to Lower Stress. 2017.

27. Papastavrou E, Tsangari H, Karayiannis G, Papacostas S, Efstathiou G, Sourtzi P. Caring and coping: The dementia caregivers. Aging \& Mental Health. 2011;15(6):702-11.

28. Rattinger GB, Fauth EB, Behrens S, Sanders C, Schwartz S, Norton MC, et al. Closer caregiver and care-recipient relationships predict lower informal costs of dementia care: The Cache County Dementia Progression Study. Alzheimer's \& Dementia. 2016;12(8):917-24.

29. Lavoie-Vaughan N. A critical analysis and adaptation of a clinical practice guideline for the management of behavioral problems in residents with dementia in long-term care. Nursing Clinics of North America. 2014;49(1):105-13.

30. Mahmoudi M, Mohammadkhan P, Ghobari Bonab B, Bagheri F. Effectiveness of CognitiveBehavioral Group Therapy on Guilt Feeling Among Family Caregivers of Patients With Alzheimer's Disease. Practice in Clinical Psychology. 2017;5(3):203-10.

\section{Tables}

Table 1. Sociodemographic characteristics of participants (qualitative study) 


\begin{tabular}{|c|c|c|}
\hline$N(\%)$ & Variable & \\
\hline $25(86.2)$ & Female & \multirow[t]{2}{*}{ Sex } \\
\hline $4(13.7)$ & Male & \\
\hline $3(10.3)$ & $18-27$ & \multirow[t]{4}{*}{ Age (years) } \\
\hline $4(13.8)$ & $28-37$ & \\
\hline $8(27.6)$ & $38-47$ & \\
\hline $14(48.2)$ & $47>$ & \\
\hline $23(79.2)$ & Married & \multirow[t]{2}{*}{ Marital status } \\
\hline $6(20.7)$ & Single & \\
\hline $2(6.9)$ & No formal education & \multirow{4}{*}{ Education Level } \\
\hline $8(27.6)$ & Less than 12 years & \\
\hline $12(41.3)$ & High School Diploma & \\
\hline $7(24.1)$ & Some University/Graduate & \\
\hline $12(41.3)$ & Formal caregiving & \multirow[t]{2}{*}{ Kind of caregiving } \\
\hline $17(58.6)$ & Family caregiver & \\
\hline $4(23.5)$ & Wife & \multirow{5}{*}{ Relationship to patient (Family Caregivers) } \\
\hline $9(52.9)$ & Daughter & \\
\hline $1(5.9)$ & Son & \\
\hline $2(11.8)$ & Family & \\
\hline $1(5.9)$ & Friend & \\
\hline $29(100)$ & & \\
\hline
\end{tabular}

Table 2: Sociodemographic characteristics of participants (quantitative study) 


\begin{tabular}{|c|c|c|}
\hline Variable & Number of respondents & Percentages \\
\hline \multicolumn{3}{|l|}{ Sex } \\
\hline Female & 28 & 73.7 \\
\hline Male & 10 & 27.3 \\
\hline \multicolumn{3}{|l|}{ Education Level } \\
\hline Less than 12 years & 12 & 31.6 \\
\hline High School Diploma & 13 & 34.2 \\
\hline Some University/Graduate & 13 & 34.2 \\
\hline \multicolumn{3}{|l|}{ Marital status } \\
\hline Single & 6 & 15.8 \\
\hline Married & 28 & 73.7 \\
\hline Widow & 1 & 2.6 \\
\hline divorced & 3 & 7.9 \\
\hline \multicolumn{3}{|c|}{ previous experience of caring for Alzheimer's patients } \\
\hline \multicolumn{3}{|l|}{ Yes } \\
\hline \multirow[t]{2}{*}{ No } & 15 & 39.5 \\
\hline & 23 & 60.5 \\
\hline \multicolumn{3}{|l|}{ Kind of caregiving } \\
\hline Family caregiver (informal- family relationship) & 6 & 15.8 \\
\hline Formal caregiver (No family relationship) & 32 & 84.2 \\
\hline \multicolumn{3}{|l|}{ caregivers sent by service companies } \\
\hline \multicolumn{3}{|l|}{ Yes } \\
\hline \multirow[t]{2}{*}{ No } & 5 & 13.2 \\
\hline & 33 & 86.8 \\
\hline Total & 38 & 100 \\
\hline
\end{tabular}

Table 3 -The mean scores of knowledge and practice before and after the intervention 


\begin{tabular}{|c|c|c|c|c|c|}
\hline \multirow{2}{*}{ score } & \multicolumn{2}{|c|}{$\begin{array}{l}\text { before } \\
\text { intervention }\end{array}$} & \multicolumn{2}{|c|}{$\begin{array}{l}\text { After } \\
\text { intervention }\end{array}$} & \multirow[t]{2}{*}{$\begin{array}{l}\mathrm{P} \text { - } \\
\text { value }\end{array}$} \\
\hline & Mean & SD & Mean & SD & \\
\hline knowledge & 52.8 & 12.6 & 61.6 & 17.6 & .02 \\
\hline $\begin{array}{l}\text { caregiving based on the physical and daily needs of the } \\
\text { patient }\end{array}$ & 65.1 & 12.7 & 70.7 & 13.6 & .035 \\
\hline $\begin{array}{l}\text { caregiving based on practice and psychological } \\
\text { disorders of the patient }\end{array}$ & 63.02 & 12.4 & 71.3 & 12.03 & .007 \\
\hline $\begin{array}{l}\text { caregiving based on risky and unsafety behaviors of the } \\
\text { patient }\end{array}$ & 73.1 & 19.1 & 81.5 & 20.7 & .03 \\
\hline Total caregiver's practice & 65.1 & 9.7 & 72.02 & 11.01 & .003 \\
\hline
\end{tabular}

Table 4 Correlation coefficients of the knowledge score and total caregiver practice score with age, years of caregiving, daily caregiving hours, duration of caregiving (current patient), and education level

$\begin{array}{llllll} & \begin{array}{l}\text { duration of caring } \\ \text { for this } \\ \text { patient(year) }\end{array} & \begin{array}{l}\text { The overall } \\ \text { hours of } \\ \text { daily } \\ \text { caregiving }\end{array} & \begin{array}{l}\text { duration of caring } \\ \text { (year) }\end{array} & \text { age } & \text { variable } \\ \text { Lducation } & & & \end{array}$

\begin{tabular}{|c|c|c|c|c|c|c|c|c|c|c|}
\hline$r$ & $P$ & $r$ & $\mathrm{P}$ & $r$ & $P$ & $r$ & $P$ & $r$ & $P$ & Knowledge \\
\hline .167 & .32 & .177 & .32 & .193 & .29 & .279 & .049 & .109- & .54 & \\
\hline .280 & .044 & $.223-$ & .11 & .386 & .03 & .250 & .12 & $.096-$ & .59 & $\begin{array}{l}\text { Total } \\
\text { caregiver's } \\
\text { practice } \\
\text { score }\end{array}$ \\
\hline
\end{tabular}

Table 5 -The extended PLST model 
1. Maximize safe function by supporting losses
- Use an unhurried, consistent, and familiar routine.

- Avoid attempts to reason or asking the person to "try

harder."

- Avoid attempts to teach new skills.

- Alternate high- and low-level stimulation activities.

- Limit choices on the basis of ability.

- Schedule planned rest periods during the day.

- Adjust levels of activity and stimulation on the basis of

stress responses.

- Evaluate for possible physical stressors (e.g., urge to

empty bladder or bowels, hunger, pain).
2. Provide unconditional positive regard

- Use uncomplicated, comprehensible language.

- Use gentle touch.

- Eliminate negative comments or corrections.

- Make use of distraction or acceptance rather than

argument.

- Allow the person to complete self-care activities as

able with minimal directions or taking over.

3. Use anxiety and avoidance to gauge activity and stimulation levels
- Look for early signs of anxious behavior (e.g., toe

tapping, pacing, worried expression).

- Keep records of activities and times of day with increased anxiety.

- Listen carefully to repeated phrases or jargon.

- Attend to repeated behaviors as expressions of anxiety 
(e.g., searching for lost items).

5. Modify environments to support losses and enhance safety
- Assess the environment for hazards or barriers.

- Remove access to potentially dangerous items (e.g.,

guns, power tools, cleaning products, motorized vehicles).

- Simplify the environment to reduce stimulation and

potential misinterpretation (e.g., mirrors, pictures,

clutter, television).

- Provide environmental cues to increase orientation

(e.g., large clocks, signs).
6. Provide ongoing education, support, care, and problem-solving.
- Provide referrals to community resources for health education (physical and mental), assistance. physical care, respite, and support groups

\section{Show respect for the patient's religious beliefs}

\section{A. Establish hygiene routines based on patient's beliefs}

B. Provide opportunities for the patient to attend familiar cultural and religious activities which can help the patient to remember old memories

1. Do not argue with the patient regarding the time, place, and the sequence of performing prayers or any religious rituals

2. Perform prayers when the patient is present

3. Play Quran recitation at the specific times of the day

1. Keep the surroundings and the patient clean and hygienic as much as possible

1. Put Henna on a female patient

2. Attend poetry nights especially for male patients

3. (Reciting Shahnameh and Hafez) Schedule outings and short excursions with the caregiver/s 